\title{
Antioxidant and Anti-Inflammatory Effects of Herbal Formula SC-E3 in Lipopolysaccharide-Stimulated RAW 264.7 Macrophages
}

\author{
Soo Chil Lee, Young-Won Kwon, Ju-Yeon Park, Sung Yun Park, \\ Ju-Hee Lee, and Sun-Dong Park \\ College of Korean Medicine, Dongguk University, Goyang 10326, Republic of Korea \\ Correspondence should be addressed to Ju-Hee Lee; jh1548@dongguk.ac.kr and Sun-Dong Park; sundong@dongguk.ac.kr
}

Received 28 May 2017; Revised 10 August 2017; Accepted 21 August 2017; Published 15 October 2017

Academic Editor: Shao-Hsuan Kao

Copyright (C) 2017 Soo Chil Lee et al. This is an open access article distributed under the Creative Commons Attribution License, which permits unrestricted use, distribution, and reproduction in any medium, provided the original work is properly cited.

\begin{abstract}
SC-E3 is a novel herbal formula composed of five oriental medicinal herbs that are used to treat a wide range of inflammatory diseases in Korean traditional medicine. In this study, we sought to determine the effects of SC-E3 on free radical generation and inflammatory response in lipopolysaccharide- (LPS-) treated RAW 264.7 macrophages and the molecular mechanism involved. The ethanol extract of SC-E3 showed good free radical scavenging activity and inhibited LPS-induced reactive oxygen species generation. SC-E3 significantly inhibited the production of the LPS-induced inflammatory mediators, nitric oxide and prostaglandin $\mathrm{E}_{2}$, by suppressing the expressions of inducible nitric oxide synthase and cyclooxygenase-2, respectively. SC-E3 also prevented the secretion of the proinflammatory cytokines, IL- $1 \beta$, TNF- $\alpha$, and IL- 6 , and inhibited LPS-induced NF- $\kappa$ B activation and the mitogen-activated protein kinase (MAPK) pathway. Furthermore, SC-E3 induced the expression of heme oxygenase-1 (HO1) by promoting the nuclear translocation and transactivation of Nrf2. Taken together, these results suggest that SC-E3 has potent antioxidant and anti-inflammatory effects and that these effects are due to the inhibitions of NF- $\kappa \mathrm{B}$ and MAPK and the induction of Nrf2-mediated HO-1 expression in macrophages. These findings provide scientific evidence supporting the potential use of SC-E3 for the treatment and prevention of various inflammatory diseases.
\end{abstract}

\section{Introduction}

Interest in diseases and health problems and desires for a better quality of life are rising along with an increase in life expectancy. Since most disease is associated with the disruption of homeostasis and chronic inflammation, oxidative stress and inflammation have become major health issues. Oxidative stress is defined as an imbalance between the production of reactive oxygen species (ROS) and the capacity of cellular antioxidant defenses [1]. Excessive ROS generation damages cellular macromolecules, including proteins, carbohydrates, lipids, and nucleic acids, dysregulates cellular signaling events, and ultimately leads to the pathogeneses and progressions of inflammatory diseases [2]. Although inflammation and oxidative stress are often by-products of normal cellular processes, excessive oxidative stress and chronic inflammation can cause chronic diseases, such as diabetes, cancer, degenerative diseases, and obesity, and accelerate the aging process [3]. Therefore, it is important that oxidative stress and inflammation be adequately controlled to prevent the progressions of chronic diseases.

Macrophages are key modulator and effector cells in immune response and play critical roles in the initiation, maintenance, and resolution of inflammation [4]. When exposed to inflammatory stimuli, macrophages become activated and then increase the productions of inflammatory mediators, such as nitric oxide $(\mathrm{NO})$ and prostaglandin $\mathrm{E}_{2}\left(\mathrm{PGE}_{2}\right)$, and of inflammatory cytokines, such as tumor necrosis factor(TNF-) $\alpha$, interleukin- (IL-) 1 , and IL-6 [4, 5]. These inflammatory responses have been extensively studied in RAW 264.7 macrophages stimulated by lipopolysaccharide (LPS, an endotoxin obtained from gram-negative bacteria) [6].

Traditional Korean herbal medicines have long been used to treat various inflammatory diseases. Over the past decades, 
TABLE 1: The compositions of the three herbal formulas examined.

\begin{tabular}{|c|c|c|}
\hline Latin name & Scientific name (family name) & Ratio \\
\hline \multicolumn{3}{|l|}{ SC-E1 } \\
\hline Gypsum Fibrosum & Gypsum & 16 \\
\hline Puerariae Radix & Pueraria lobata Ohwi (Leguminosae) & 6 \\
\hline Gardeniae Fructus & Gardenia jasminoides Ellis (Rubiaceae) & 6 \\
\hline Glycyrrhizae Radix et Rhizoma & Glycyrrhiza uralensis Fischer (Leguminosae) & 2 \\
\hline Platycodi Radix & Platycodon grandiflorum A. De Candolle (Campanulaceae) & 3 \\
\hline \multicolumn{3}{|l|}{ SC-E2 } \\
\hline Bupleuri Radix & Bupleurum falcatum Linne (Umbelliferae) & 6 \\
\hline Coptidis Rhizoma & Coptidis japonica Makino (Ranunculaceae) & 2 \\
\hline Gardeniae Fructus & Gardenia jasminoides Ellis (Rubiaceae) & 6 \\
\hline Glycyrrhizae Radix et Rhizoma & Glycyrrhiza uralensis Fischer (Leguminosae) & 2 \\
\hline Platycodi Radix & Platycodon grandiflorum A. De Candolle (Campanulaceae) & 3 \\
\hline \multicolumn{3}{|l|}{ SC-E3 } \\
\hline Bupleuri Radix & Bupleurum falcatum Linne (Umbelliferae) & 3 \\
\hline Coptidis Rhizoma & Coptidis japonica Makino (Ranunculaceae) & 1 \\
\hline Gardeniae Fructus & Gardenia jasminoides Ellis (Rubiaceae) & 3 \\
\hline Rhei Rhizoma & Rheum palmatum Linne (Polygonaceae) & 1 \\
\hline Puerariae Radix & Pueraria lobata Ohwi (Leguminosae) & 3 \\
\hline
\end{tabular}

the usages of herbs or traditional Korean herbal medicines that are complementary and/or alternative medicines to the management of inflammation have increased because of concerns about the adverse side effects of nonsteroidal antiinflammatory drugs [7]. Accordingly, we initiated this study to identify traditional Korean herbal medicines that might be useful for the prevention or treatment of inflammatory conditions. Sanghanron (Shang Han Lun) and Geumgweyoryak (Jin Gui Yao Lue) are ancient Chinese medical books written by Jang Jung Kyung (Zhang Zhong-jing) and constitute the basis of traditional Korean herbal prescriptions [8, 9]. We designed three novel anti-inflammatory herbal formulas called SC-E1, SC-E2, and SC-E3, based on prescriptions for treating inflammation in the Sanghanron and Geumgweyoryak, and each herbal formula was derived based on the daily doses of five herbal medicines (Table 1). Preliminary in vitro screening showed that SC-E3, which contains five medicinal herbs (Bupleuri Radix, Coptidis Rhizoma, Gardeniae Fructus, Rhei Rhizoma, and Puerariae Radix), exhibited greatest free radical scavenging ability and most inhibited NO production. Therefore, in the present study, we evaluated the antioxidant and anti-inflammatory effects of SC-E3 in LPSstimulated RAW 264.7 macrophages and sought to identify the mechanisms responsible for its effects.

\section{Materials and Methods}

2.1. Chemicals and Reagents. Dulbecco's Modified Eagle's Medium was purchased from Welgene (Gyeongsan, Korea) and fetal bovine serum (FBS) from Gibco BRL (Gaithersburg, MD, USA). ELISA kits for IL- $1 \beta$, TNF- $\alpha$, and IL-6 were obtained from Ab Frontier (Seoul, Korea) and $\mathrm{PGE}_{2}$ was purchased from R\&D Systems (Minneapolis, MN, USA). Primary antibodies, that is, anti-HO-1, anti-COX-2,
anti-iNOS, anti-p-I $\kappa \mathrm{B}-\alpha$, anti-p-NF- $\kappa \mathrm{B}$ (p65), and anti-Nrf2 and secondary antibodies were purchased from Santa Cruz Biotechnology (Santa Cruz, CA, USA). Dimethyl sulfoxide (DMSO) was purchased from Junsei Chemical Co. (Tokyo, Japan), and LPS (E. coli 055:B5), geniposide, puerarin, 3-(4,5-dimethylthiazol-2-yl)-2,5-diphenyl-tetrazolium bromide (MTT), Griess reagent, 4,6-diamidino-2-phenylindole (DAPI), and other reagents were purchased from SigmaAldrich (St. Louis, MO, USA).

2.2. Isolation and Structural Identification of SC-E3. SC-E3 was formulated from five oriental medicinal herbs, that is, Bupleuri Radix (voucher specimen number: DUMCKM2015107), Coptidis Rhizoma (voucher specimen number: DUMCKM2015-083), Gardeniae Fructus (voucher specimen number: DUMCKM2015-069), Rhei Rhizoma (voucher specimen number: DUMCKM2015-017), and Puerariae Radix (voucher specimen number: DUMCKM2015-001). All were purchased as dried herbs from Omniherb (Daegu, Korea) in accord with the good manufacturing practices (GMP) procedures certified by the Korea Food and Drug Administration (KFDA) and authenticated by Professor Sun-Dong Park (Department of Prescriptions, College of Korean Medicine, Dongguk University). Voucher specimens were deposited at the College of Korean Medicine, Dongguk University.

Briefly, a mixture of dried Bupleuri Radix, Coptidis Rhizoma, Gardeniae Fructus, Rhei Rhizoma, and Puerariae Radix (100 g; weight ratios $3: 1: 3: 1: 3$ ) was macerated in $800 \mathrm{~mL}$ of $70 \%$ ethanol, stirred for $24 \mathrm{~h}$ at room temperature (RT), and filtered twice through an $8 \mu \mathrm{m}$ Whatman filter paper. After rotary evaporation at $40 \sim 45^{\circ} \mathrm{C}$, the concentrate was lyophilized using a freeze dryer (EYELA, Japan). The yield of the SC-E3 extract (dried powder) was $15.2 \%$ by weight with respect to the dried starting materials. 
2.3. High-Performance Liquid Chromatography (HPLC). SCE3 was analyzed by a Dionex Ultimate 3000 HPLC system (Thermo Fisher Scientific, Waltham, MA, USA) equipped with a binary solvent delivery pump, a vacuum degasser, an autosampler, a temperature controlled column oven $\left(30^{\circ} \mathrm{C}\right)$, and a diode array spectrophotometric detector (DAD). Geniposide and puerarin (Sigma-Aldrich) were used as standards. Separations were performed using a VDSpher EC-C18 column $(4.6 \mathrm{~mm} \times 250 \mathrm{~mm}, 5 \mu \mathrm{m}$, VDSoptilab, Germany). The mobile phase consisted of $0.3 \%$ trifluoroacetic acid (A) and acetonitrile (B), and gradient elution was performed as follows: $10 \%$ B for $0-1 \mathrm{~min}, 10-50 \%$ B for $1-25 \mathrm{~min}, 90 \% \mathrm{~B}$ for 25-35 $\mathrm{min}$, and $90-10 \% \mathrm{~B}$ for $35-40 \mathrm{~min}$. The flow rate and injection volume were $0.8 \mathrm{~mL} / \mathrm{min}$ and $10 \mu \mathrm{L}$, respectively. The assays were monitored at $240 \mathrm{~nm}$ and all data were acquired and processed using Chromeleon 6.8 software.

2.4. DPPH Radical Scavenging Activity Assay. A 2,2-Diphenyl-1-picrylhydrazyl (DPPH) assay was conducted using a slight modification of the method described by Gyamfi et al. [10]. Briefly, beforehand DPPH solution (0.1 mM) was prepared by dissolving $3.94 \mathrm{mg} \mathrm{DPPH}$ in $100 \mathrm{~mL}$ of ethanol. Various concentrations of SC-E3 $(50-500 \mu \mathrm{g} / \mathrm{mL})$ were incubated in $50 \mathrm{mM}$ Tris- $\mathrm{HCl}(\mathrm{pH} 7.4)$ containing $0.1 \mathrm{mM} \mathrm{DPPH}$ for $30 \mathrm{~min}$ in the dark. The control was prepared as above but without SC-E3. Absorbances (Abs.) were measured at $517 \mathrm{~nm}$ using a microplate reader. Scavenging activity was defined as the percentage of DPPH radicals scavenged and was calculated using the following equation:

$$
\begin{aligned}
& \text { Scavenging effect }(\%) \\
& \qquad=\left[\frac{(\text { control Abs. }- \text { sample Abs. })}{(\text { control Abs. })}\right] \times 100 .
\end{aligned}
$$

2.5. Superoxide Anion Free Radical Scavenging Activity Assay. Scavenging activities for the superoxide anion free radical were assessed as previously described with slight modification [11]. Briefly, samples of SC-E3 (0, 50, 100, 300, or $500 \mu \mathrm{g} / \mathrm{mL}$ ) were added to a reaction solution containing $30 \mu \mathrm{L}$ of $30 \mathrm{mM}$ EDTA ( $\mathrm{pH} 7.4$ ), $10 \mu \mathrm{L}$ of $30 \mathrm{mM}$ hypoxanthine in $50 \mathrm{mM} \mathrm{NaOH}$, and $200 \mu \mathrm{L}$ of $1.42 \mathrm{mM}$ nitro blue tetrazolium (NBT). This solution was preincubated at RT for $3 \mathrm{~min}$ and then $10 \mu \mathrm{L}$ of $1 \mathrm{U} / \mathrm{mL}$ xanthine oxidase was added followed by $50 \mathrm{mM}$ of phosphate buffer ( $\mathrm{pH} 7.4$ ) to bring the volume up to $300 \mu \mathrm{L}$. This solution was incubated at RT for $20 \mathrm{~min}$ and then absorbance was measured at $560 \mathrm{~nm}$.

2.6. Total Polyphenol Content. The total phenolic content of SC-E3 was determined using the Folin-Ciocalteu colorimetric method as described by Ainsworth and Gillespie with slight modification [12]. Briefly, $40 \mu \mathrm{L}$ of SC-E3 was added to $200 \mu \mathrm{L}$ of Folin-Ciocalteu reagent (Sigma-Aldrich) in $1,160 \mu \mathrm{L}$ of distilled water and mixed thoroughly. The mixture was incubated for $3 \mathrm{~min}$ at RT and to this $600 \mu \mathrm{L}$ of $2 \%$ sodium carbonate was added. After $2 \mathrm{~h}$ of incubation in dark, the mixture was aliquoted into a 96-well plate and absorbance was measured at $765 \mathrm{~nm}$ using a microplate reader. Gallic acid was used as standard and total phenolic content was expressed as mg of gallic acid equivalents (GAE) per gram of SC-E3.

2.7. Total Flavonoid Content. The total flavonoid content of SC-E3 was estimated using an aluminium trichloride colorimetric method using catechin as the reference compound [13]. SC-E3 $(100 \mu \mathrm{L})$ was mixed with $400 \mu \mathrm{L}$ of distilled water and added to $30 \mu \mathrm{L}$ of $5 \%$ sodium nitride $\left(\mathrm{NaNO}_{2}\right)$. After $6 \mathrm{~min}, 30 \mu \mathrm{L}$ of $10 \%$ aluminium trichloride $\left(\mathrm{AlCl}_{3}\right)$ was added to the mixture and incubated for $5 \mathrm{~min}$, followed by the addition of $200 \mu \mathrm{L}$ of $1 \mathrm{M} \mathrm{NaOH}$. The final volume of the mixture was adjusted to $1 \mathrm{~mL}$ with distilled water and incubated for $15 \mathrm{~min}$, and then absorbance was measured at $510 \mathrm{~nm}$ using a microplate reader. Total flavonoid content was calculated using a catechin standard curve and results were expressed as $\mathrm{mg}$ of catechin equivalents (CE) per gram of SC-E3.

2.8. Cell Culture. RAW 264.7 macrophages were purchased from the American Type Culture Collection (Rockville, MD, USA) and cultured in Dulbecco's Modified Eagle's Medium, supplemented with $10 \%$ FBS and $1 \%$ penicillin-streptomycin in a humidified $5 \% \mathrm{CO}_{2}$ incubator at $37^{\circ} \mathrm{C}$.

2.9. Cell Viability. The effect of SC-E3 on cell viability was evaluated using a MTT colorimetric assay. Briefly, cells were suspended in 96-well plates at $1 \times 10^{4}$ cells/well and and treated with different concentrations of SC-E3 for $24 \mathrm{~h}$. Cells were then treated with MTT solution $(2 \mathrm{mg} / \mathrm{mL})$ for $3 \mathrm{~h}$. After removing supernatants, the formazan produced was dissolved in DMSO, and absorbance was measured at $540 \mathrm{~nm}$ using a microplate reader (Genios, Tecan, Austria).

2.10. Reactive Oxygen Species (ROS) Assessments. A fluorescent dichlorofluorescein diacetate (DCFH-DA) assay was used to access intracellular ROS concentrations. Murine macrophages were seeded on a 96-well black plate at 1 $\times 10^{5}$ cells $/ \mathrm{mL}$, and incubated with LPS $(1 \mu \mathrm{g} / \mathrm{mL})$ in the presence or absence of SC-E3 $(50,100,300$, or $500 \mu \mathrm{g} / \mathrm{mL})$. After removing medium, cells were treated with $10 \mu \mathrm{M}$ DCFH-DA in phosphate-buffered saline (PBS) for $30 \mathrm{~min}$ at $37^{\circ} \mathrm{C}$. Fluorescence was measured at excitation and emission wavelengths of $480 \mathrm{~nm}$ and $530 \mathrm{~nm}$, respectively, using a fluorescence microplate reader (Spectra Gemini, Molecular Devices).

2.11. Nitrite Assay. RAW 264.7 macrophages were pretreated with various concentrations $(50-500 \mu \mathrm{g} / \mathrm{mL})$ of SC-E3 for $1 \mathrm{~h}$ and then stimulated or not for $18 \mathrm{~h}$ with LPS $(1 \mu \mathrm{g} /$ $\mathrm{mL})$. Aliquots $(100 \mu \mathrm{L})$ of supernatants were reacted with equal volumes of Griess reagent [1\% sulfanilamide, $0.1 \% \mathrm{~N}-(1-$ naphthyl)-ethylenediamine dihydrochloride, $2.5 \%$ phosphoric acid] at $\mathrm{RT}$ for $10 \mathrm{~min}$, and nitrite concentrations were assessed by measuring absorbance at $540 \mathrm{~nm}$ with a microplate reader.

2.12. Enzyme-Linked Immunosorbent Assay (ELISA). RAW 264.7 macrophages were preincubated with various concentrations $(50-500 \mu \mathrm{g} / \mathrm{mL})$ of SC-E3 for $1 \mathrm{~h}$ and then stimulated for $18 \mathrm{~h}$ with LPS. Supernatants were harvested, and 
cytokine contents including those of IL- $1 \beta$, TNF- $\alpha$, and IL6 were assessed using ELISA kits (Ab Frontier), according to the manufacturer's instructions. $\mathrm{PGE}_{2}$ levels were measured using a $\mathrm{PGE}_{2}$ parameter assay kit (R\&D Systems), according to the manufacturer's instructions.

2.13. Nuclear and Cytosolic Fractionation. RAW 264.7 macrophages treated with or without SC-E3 were harvested and washed with PBS. Nuclear and cytoplasmic fraction of cells was conducted using NE-PER ${ }^{\mathrm{TM}}$ nuclear and cytoplasmic extraction kit (Thermo Scientific, Rockford, IL, USA) according to the manufacturer's instructions. The nuclear and cytoplasmic extracts were stored at $-80^{\circ} \mathrm{C}$ until required. Protein concentrations in extracts were quantified using a bicinchoninic acid (BCA) protein assay kit (Thermo Scientific).

2.14. Western Blot Analysis. RAW 264.7 macrophages were extracted with RIPA lysis buffer containing phosphatase and protease inhibitor cocktail (GenDEPOT, Barker, TX, USA), and total protein concentrations were then determined using a BCA protein assay kit (Thermo Scientific). Equal amounts of total proteins were separated by $10 \%$ SDS-PAGE and transferred onto polyvinylidene difluoride membranes, which were then blocked in $5 \%$ skim milk for $2 \mathrm{~h}$ at RT and incubated overnight at $4^{\circ} \mathrm{C}$ with primary antibodies against p38, iNOS, COX-2, ERK1/2, JNK, Nrf2, Lamin B, $\mathrm{HO}-1, \beta$-actin, and the phosphorylated forms of $\mathrm{p} 38$, NF$\kappa \mathrm{B}, \mathrm{I} \kappa \mathrm{B}-\alpha, \mathrm{ERK} 1 / 2$, and JNK. Membranes were then rinsed and incubated with secondary antibodies conjugated with horseradish peroxidase for $2 \mathrm{~h}$ at RT. After rinsing, bands were visualized using ECL prime solution (Amersham Bioscience, Buckinghamshire, UK). Blots were quantified by densitometry using scientific imaging software (ImageJ 1.42; $\mathrm{NIH}$, Bethesda, MD, USA) after normalizing versus $\beta$-actin, which was used a loading control.

2.15. Immunofluorescence Microscopy. To detect the nuclear translocations of NF- $\kappa$ B and Nrf2, RAW 264.7 cells were cultured directly on glass cover slips in 6-well plates and treated with $300 \mu \mathrm{g} / \mathrm{mL}$ SC-E3 in the presence or absence of LPS. Briefly, cells were fixed with methanol for $10 \mathrm{~min}$, permeabilized in PBS containing 1\% Triton X-100 for $10 \mathrm{~min}$, incubated with NF- $\kappa$ B p 65 or Nrf2 antibody $(1: 200)$ in PBS overnight at $4^{\circ} \mathrm{C}$, and labelled with fluorescein isothiocyanate- (FITC-) conjugated goat anti-rabbit IgG (1:1000, Invitrogen) for $1 \mathrm{~h}$ and DAPI (Sigma-Aldrich) for $5 \mathrm{~min}$. After mounting coverslips on glass slides using ProLong ${ }^{\circledR}$ Gold Antifade Reagent (Thermo Scientific), fluorescence images were captured using an Olympus BX50 fluorescence microscope (Olympus Optical, Tokyo, Japan).

2.16. Statistical Analysis. Results are presented as the means \pm standard deviations (SDs) of at least three independent experiments. Statistical significance was determined by oneway ANOVA followed by Tukey's multiple comparison test using GraphPad Prism software (GraphPad Software Inc., San Diego, CA, USA). Differences were considered statistically significant when $p$ values were $<0.05$.

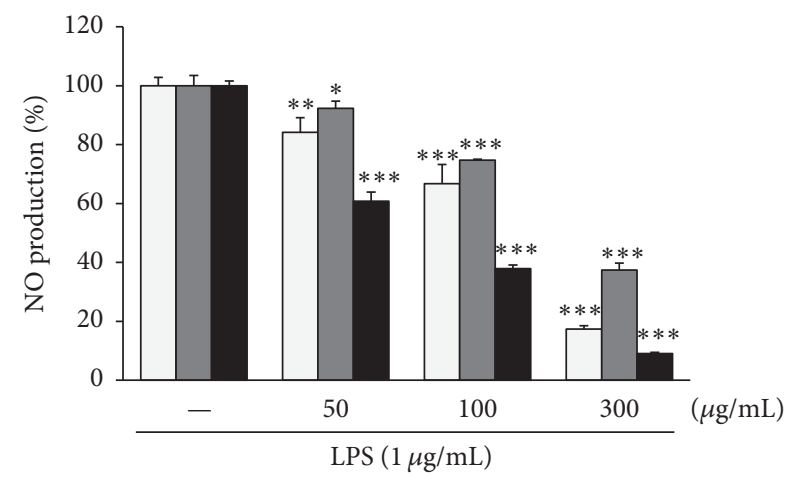

$\begin{array}{ll}\text { - } & \text { SC-E1 } \\ \text { - } & \text { SC-E2 } \\ \text { - } & \text { SC-E3 }\end{array}$

FIGURE 1: Effects of the three herbal formulas (SC-E1, SC-E2, and SC-E3) on the production of NO in LPS-stimulated RAW 264.7 macrophages. Cells were pretreated with various concentrations $(50-300 \mu \mathrm{g} / \mathrm{mL})$ of each formula for $1 \mathrm{~h}$ and then stimulated with LPS $(1 \mu \mathrm{g} / \mathrm{mL})$ for $18 \mathrm{~h}$. NO production was determined using Griess reagent. (Significant versus LPS treatment, ${ }^{*} p<0.05,{ }^{* *} p<0.01$, and ${ }^{* * *} p<0.001$.)

\section{Results}

3.1. Screening of the Effects of Novel Herbal Prescriptions. To find new antioxidant or anti-inflammatory prescription candidates, we first evaluated the free radical scavenging activities of SC-E1, SC-E2, and SC-E3 extracts. All three extracts exhibited significant, dose-dependent DPPH radical scavenging activity (Supplementary Figure 1(a) in Supplementary Material available online at https://doi.org/10.1155/ 2017/1725246). The free radical scavenging activities of the extracts in descending order were SC-E3 > SC-E1 > SC-E2. The scavenging effects of the three extracts for the superoxide anion free radical were measured, and SC-E3 was found to have the greatest scavenging activity (Supplementary Figure 1(b)). The three extracts were then screened for their inhibitory effects on NO production in LPS-stimulated RAW 264.7 macrophages. As shown in Figure 1, all extracts significantly and dose-dependently suppressed NO production, and SC-E3 had the most potent effect with an $\mathrm{IC}_{50}$ value of $73.6 \mu \mathrm{g} / \mathrm{mL}$, followed by SC-E1 $\left(\mathrm{IC}_{50}=167.8 \mu \mathrm{g} / \mathrm{mL}\right)$ and SCE2 $\left(\mathrm{IC}_{50}=232.4 \mu \mathrm{g} / \mathrm{mL}\right)$. Based on these results, SC-E3 was selected for further study.

3.2. The Antioxidant and Anti-Inflammatory Effects of SCE3 on RAW 264.7 Macrophages. The cytotoxicity of SC-E3 on RAW 264.7 cells was evaluated using a MTT assay. The results showed that SC-E3 at concentrations up to $500 \mu \mathrm{g} / \mathrm{mL}$ had no toxic effect on RAW 264.7 cells (Figure 2(a)). The antioxidant activity of SC-E3 was investigated in RAW 264.7 cells treated with LPS. As shown in Figure 2(b), LPS markedly increased intracellular ROS levels in RAW 264.7 cells versus nontreated controls. However, pretreating cells with various concentrations of SC-E3 $(50-500 \mu \mathrm{g} / \mathrm{mL})$ significantly and dose-dependently reduced LPS-induced ROS generation. In 


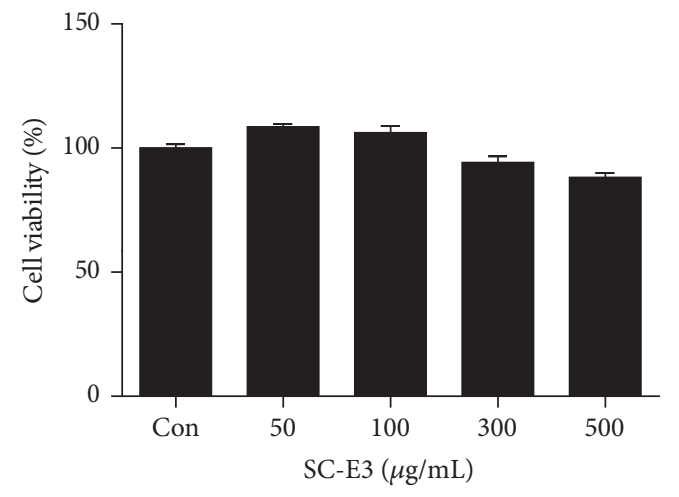

(a)

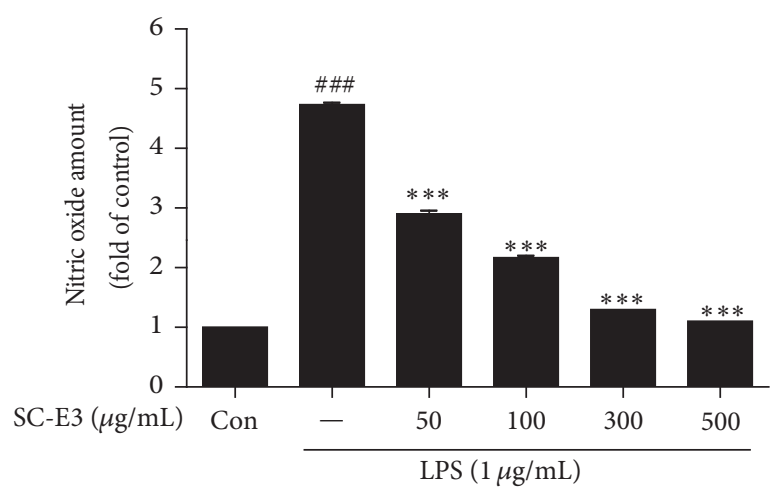

(c)

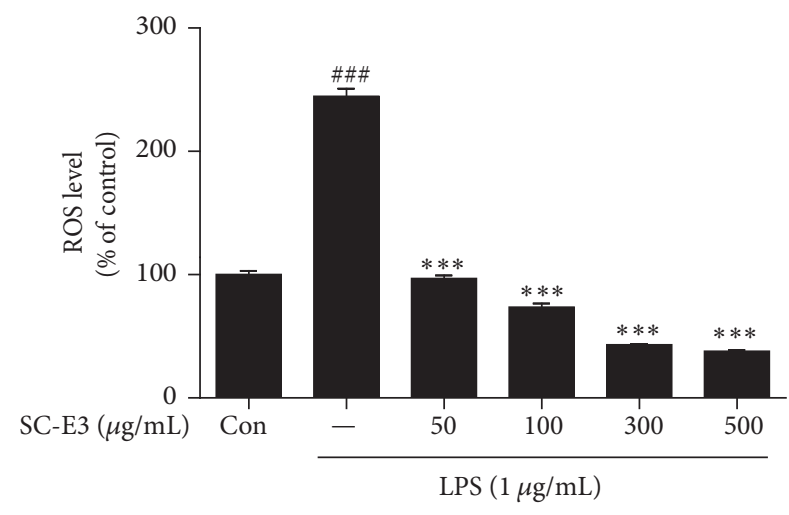

(b)

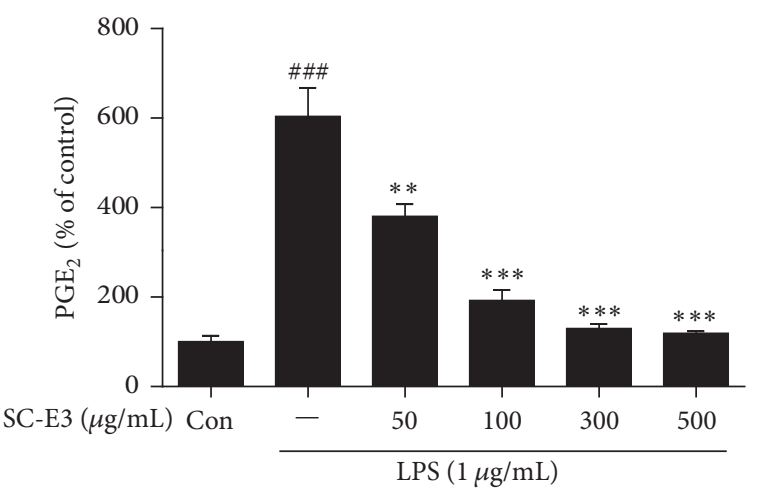

(d)

FIGURE 2: Effects of SC-E3 on ROS generation and on the productions of inflammatory mediators and cytokines in LPS-stimulated RAW 264.7 macrophages. (a) Effects of SC-E3 on viability. Cell viability was determined by MTT assay. Cells were treated with various concentrations of SC-E3 extract $(50,100,300$, or $500 \mu \mathrm{g} / \mathrm{mL})$ for $24 \mathrm{~h}$. Values were expressed as percentages of the nontreated control. (b) Effect of SC-E3 on ROS generation. Fold increases in intracellular ROS versus nontreated control were determined by measuring DCF fluorescence intensities. (c) Effects of SC-E3 on LPS-induced NO production. Cells were stimulated with $1 \mu \mathrm{g} / \mathrm{mL}$ of LPS, in the absence or presence of various concentrations $(50,100,300$, or $500 \mu \mathrm{g} / \mathrm{mL})$ of SC-E3 for $18 \mathrm{~h}$. Nitrite production was measured using Griess reagent. (d) Effects of SC-E3 on LPS-induced $\mathrm{PGE}_{2}$ production. (Significant versus the nontreated control, ${ }^{\# \# \#} p<0.001$, significant versus LPS treatment, ${ }^{* *} p<0.01$ and ${ }^{* * *} p<0.001$.)

particular, at a concentration of $50 \mu \mathrm{g} / \mathrm{mL}$ SC-E3 suppressed ROS production to the control level. To assess the antioxidant effect of SC-E3 further, its total phenolic and total flavonoid contents were estimated using gallic acid and catechin calibration curves, respectively. The results showed that total phenolic and flavonoid contents of SC-E3 were $11.53 \pm 0.61$ and $7.04 \pm 0.07 \mathrm{mg} / \mathrm{g}$, respectively. Next, we examined the anti-inflammatory effect of SC-E3 by investigating the levels of the proinflammatory mediators $\mathrm{NO}$ and $\mathrm{PGE}_{2}$ and of the proinflammatory cytokines IL- $1 \beta$, TNF- $\alpha$, and IL- 6 in LPSstimulated RAW 264.7 macrophages. As shown in Figures 2(c) and 2(d), pretreatment with SC-E3 dose-dependently suppressed the LPS-induced productions of $\mathrm{NO}$ and $\mathrm{PGE}_{2}$. In particular, SC-E3 at 300 or $500 \mu \mathrm{g} / \mathrm{mL}$ inhibited these productions to an extent similar to that of the nontreated control. In addition, pretreatment with SC-E3 significantly reduced LPS-induced increases in the levels of IL- $1 \beta$, TNF$\alpha$, and IL-6 (Figure 3).
3.3. The Inhibitory Effect of SC-E3 on the Expressions of iNOS and COX-2 in LPS-Stimulated RAW 264.7 Macrophages. We also evaluated the effects of SC-E3 on the protein levels of iNOS and COX-2, which are involved in the productions of $\mathrm{NO}$ and $\mathrm{PGE}_{2}$, respectively, in LPS-stimulated RAW 264.7 macrophages. As shown in Figures 4(a) and 4(b), LPS increased the expressions of iNOS and COX-2 in macrophages and these augmentations were reduced dosedependently by pretreating SC-E3, particularly at SC-E3 concentrations of 300 or $500 \mu \mathrm{g} / \mathrm{mL}$.

3.4. Effect of SC-E3 on Activation of the MAPK Signaling Pathway in LPS-Stimulated RAW 264.7 Macrophages. To understand the molecular mechanisms responsible for the anti-inflammatory effects of SC-E3, we examined whether SC-E3 affected MAPK signaling pathways in LPS-stimulated RAW 264.7 macrophages by western blot. ERK1/2, JNK, and p38 (the main kinases of the MAPK pathway) were 


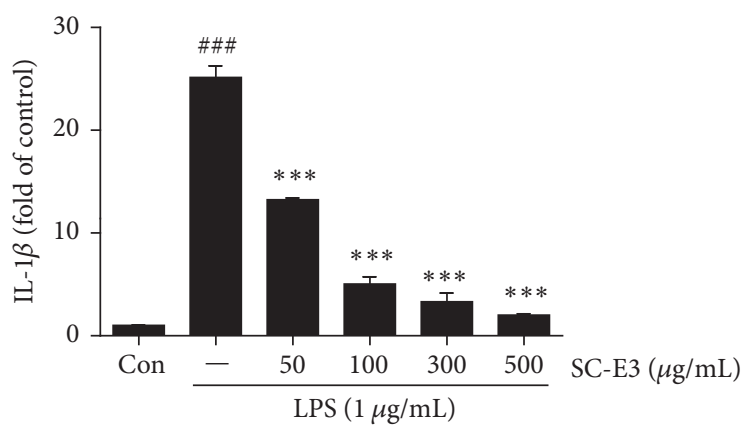

(a)

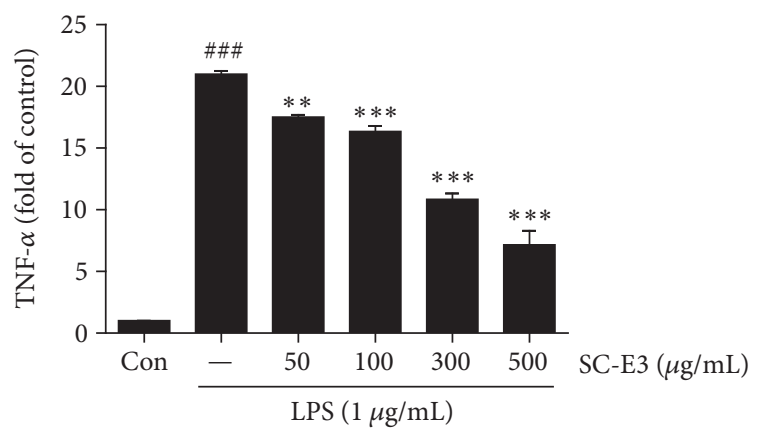

(b)

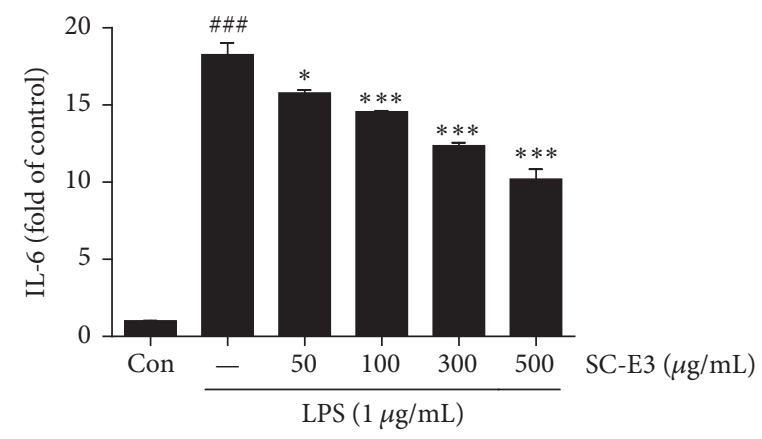

(c)

FIGURE 3: Effects of SC-E3 on LPS-induced proinflammatory cytokine production. Extracellular levels of IL-1 $\beta$ (a), TNF- $\alpha$ (b), and IL-6 (c) were measured using ELISA kits. (Significant versus the nontreated control, ${ }^{\# \#} p<0.001$, significant versus LPS treatment, ${ }^{*} p<0.05$, ${ }^{* *} p<0.01$, and ${ }^{* * *} p<0.001$.)
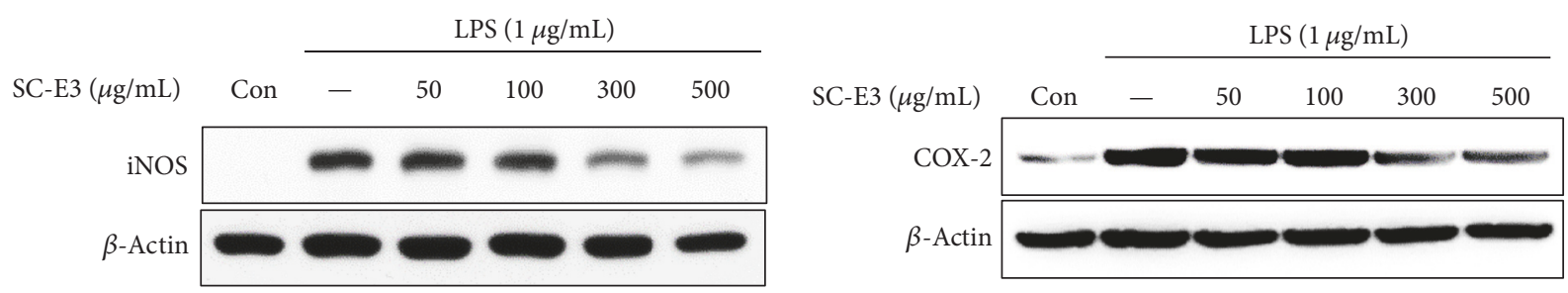

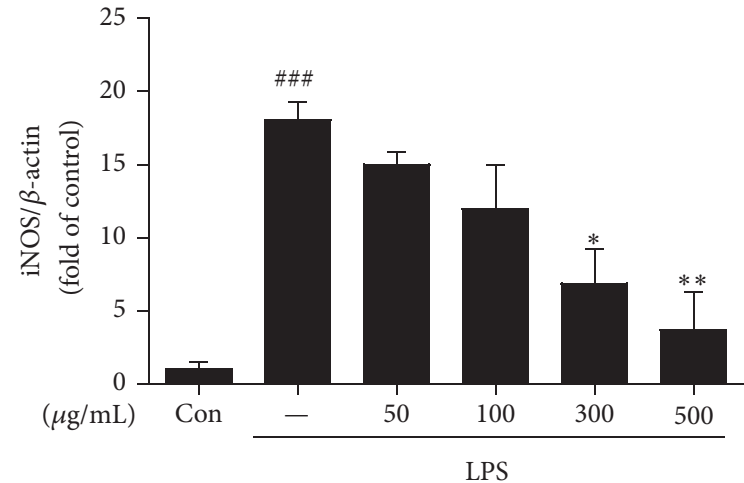

(a)

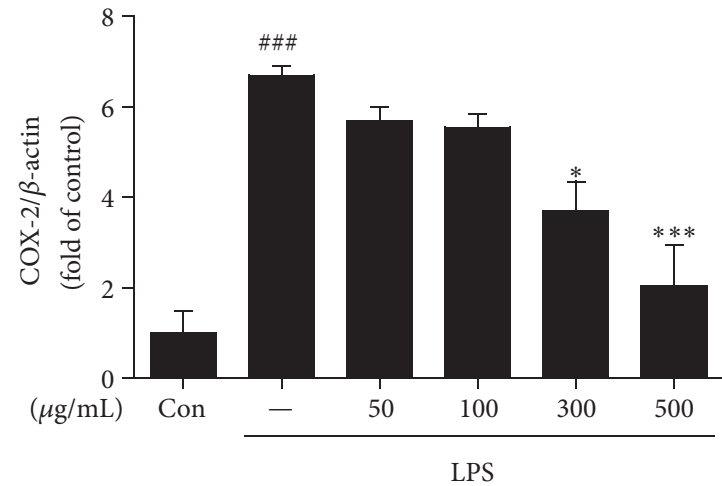

(b)

FIGURE 4: Effects of SC-E3 on the LPS-induced expressions of iNOS and COX-2 proteins in RAW 264.7 macrophages. Protein expressions of iNOS and COX-2 in RAW 264.7 macrophages incubated with different concentrations of SC-E3 (50, 100, 300, or 500 $\mu \mathrm{g} / \mathrm{mL})$ with or without LPS $(1 \mu \mathrm{g} / \mathrm{mL})$ for $24 \mathrm{~h}$ were assessed by western blot. The results showed that SC-E3 reduced the protein levels of iNOS (a) and COX-2 (b). (Significant versus nontreated control, ${ }^{\# \# *} p<0.001$, versus LPS treatment, ${ }^{*} p<0.05,{ }^{* *} p<0.01$, and ${ }^{* * *} p<0.001$.) 


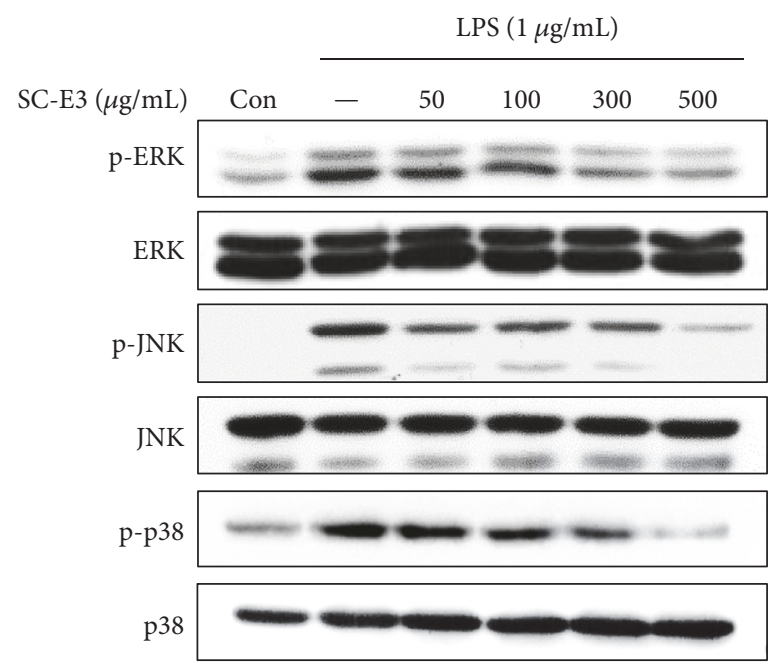

FIGURE 5: Effects of SC-E3 on MAPK pathway activation in LPS-stimulated RAW 264.7 macrophages. Cells were pretreated with different concentrations of SC-E3 $(50,100,300$, or $500 \mu \mathrm{g} / \mathrm{mL})$ for $12 \mathrm{~h}$ and then stimulated with LPS $(1 \mu \mathrm{g} / \mathrm{mL})$ for $1 \mathrm{~h}$. Western blotting was performed with antibodies for p-ERK, ERK, p-JNK, JNK, p-p38, and p38.

phosphorylated by LPS stimulation and SC-E3 pretreatment dose-dependently reduced phosphorylation of these kinases, without altering their total form (Figure 5).

\subsection{Effect of SC-E3 on NF- $\kappa B$ Activation in LPS-Stimulated} $R A W 264.7$ Macrophages. NF- $\kappa \mathrm{B}$ activation plays an important role in the regulations and transcriptions of many genes that act as mediators of inflammatory response [14]. To determine whether SC-E3 influences the activation of NF- $\kappa \mathrm{B}$ signaling in LPS-stimulated RAW 264.7 macrophages, cells were pretreated with SC-E3 for $18 \mathrm{~h}$ and then treated with LPS $(1 \mu \mathrm{g} / \mathrm{mL})$ for $1 \mathrm{~h}$. As shown in Figure 6(a), western blotting showed that the phosphorylation of $\mathrm{I} \kappa \mathrm{B}-\alpha$ and NF- $\kappa \mathrm{B}$ was increased after LPS stimulation, and this change was inhibited by pretreating SC-E3. In addition, we also confirmed that pretreatment with SC-E3 at $300 \mu \mathrm{g} / \mathrm{mL}$ suppressed the nuclear translocation of NF- $\kappa \mathrm{B}$ under LPS-induced inflammatory condition by fluorescence immunostaining (Figure 6(b)).

3.6. Effect of SC-E3 on HO-1 Expression and Nrf2 Activation in $R A W 264.7$ Macrophages. To determine whether the antioxidant and anti-inflammatory effects of SC-E3 are mediated by $\mathrm{HO}-1$ induction, we analyzed HO-1 expression in RAW 264.7 macrophages by western blot. As shown in Figure 7(a), treatment with SC-E3 for $18 \mathrm{~h}$ increased HO-1 protein levels in a dose-dependent manner, and this was particularly evident at SC-E3 concentrations of 300 and $500 \mu \mathrm{g} / \mathrm{mL}$. At a concentration of $300 \mu \mathrm{g} / \mathrm{mL}, \mathrm{HO}-1$ expression increased with time and this increased expression was sustained for $8 \mathrm{~h}$ to $24 \mathrm{~h}$ after treating cells with SC-E3 (Figure $7(\mathrm{~b})$ ). To investigate the molecular mechanism responsible for this upregulation of HO-1 by SC-E3, we assessed the nuclear translocation of Nrf2 in RAW 264.7 macrophages by western blot. As shown in Figure 7(c), nuclear Nrf2 levels were increased by SC-E3 and peaked after $1 \mathrm{~h}$ of SC-E3 treatment. Consistent with these results, fluorescence immunostaining showed that treatment with $300 \mu \mathrm{g} / \mathrm{mL}$ SC-E3 led to the translocation of Nrf2 from the cytoplasm into the nucleus (Figure $7(\mathrm{~d})$ ). To demonstrate a direct link between $\mathrm{HO}$ 1 protein expression and LPS-induced NO production, we examined the effect of SC-E3 on LPS-induced NO production in the presence of SnPP (a HO-1 inhibitor). Inhibition of HO-1 induction by SnPP increased nitrite levels in SC-E3 pretreated macrophages under LPS-induced inflammatory conditions (Figure 7(e)), but SnPP did not fully reverse the inhibitory effects of SC-E3. These results suggest that the antiinflammatory effect of SC-E3 is mediated, at least in part, by $\mathrm{HO}-1$ induction through $\mathrm{Nrf} 2$ translocation.

3.7. Identification of Compounds from SC-E3 Extract. For quantitative HPLC analysis, we selected geniposide from Gardeniae Fructus and puerarin from Puerariae Radix and Bupleuri Radix as controls. The concentrations of geniposide and puerarin in SC-E3 were determined using calibration curves prepared using the geniposide and puerarin standards. Calibration curves of geniposide and puerarin showed good linearity with respect to concentration (correlation coefficients $\left.\left(r^{2}\right) \geq 0.9996\right)$. The retention times of geniposide and puerarin were 12.173 and $11.823 \mathrm{~min}$, respectively, and the amounts of geniposide and puerarin in SC-E3 extract were $88.9 \mathrm{mg} / \mathrm{g}$ and $57.1 \mathrm{mg} / \mathrm{g}$, respectively (Figure 8(a)). Furthermore, GC-MS was applied to identify the compositions of the fatty acids in SC-E3 extract and pentadecanoic acid, palmitic acid, linoleic acid, and oleic acid were detected (Figure 8(b)).

\section{Discussion}

The present study was undertaken to identify new prescriptions for the prevention or treatment of inflammatory conditions based on traditional Korean herbal medicines. These efforts resulted in the development of a novel herbal formula called SC-E3, which is comprised of the following five medicinal herbs: Bupleuri Radix, Coptidis Rhizoma, Gardeniae Fructus, Rhei Rhizoma, and Puerariae Radix. SC-E3 


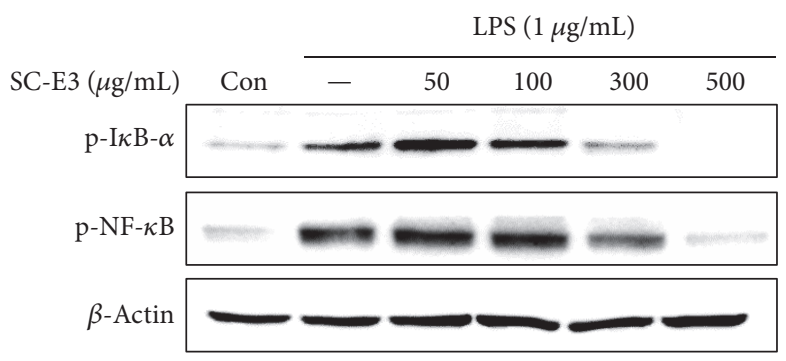

(a)
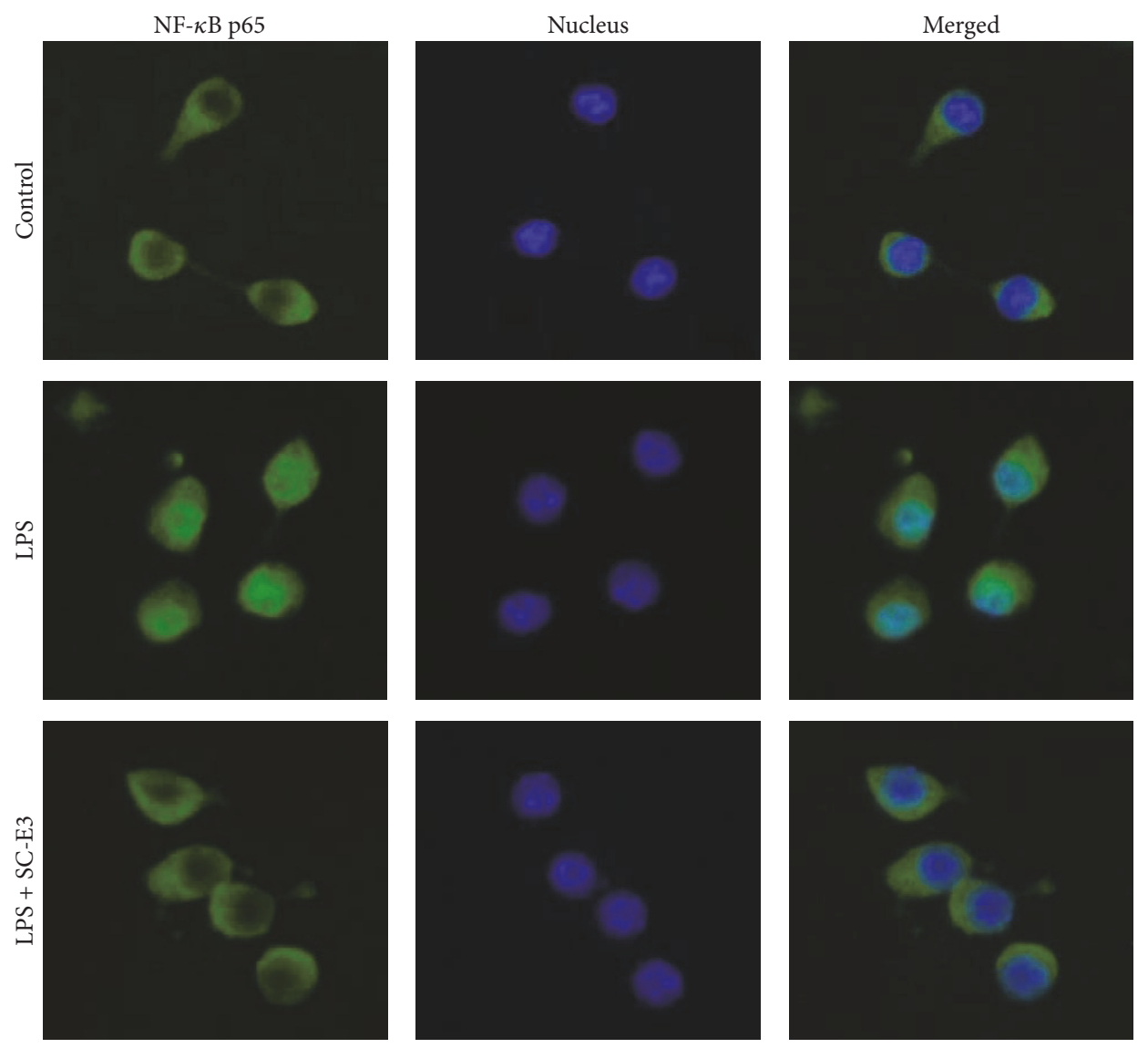

(b)

FIGURE 6: Effects of SC-E3 on NF- $\kappa$ B pathway activation by LPS. RAW 264.7 cells were pretreated with SC-E3 (300 $\mu \mathrm{g} / \mathrm{mL})$ for $18 \mathrm{~h}$ and then stimulated with LPS $(1 \mu \mathrm{g} / \mathrm{mL}$ ) for $1 \mathrm{~h}$. (a) Cell lysates were subjected to western blot analysis to determine the protein levels of p-NF- $\kappa \mathrm{B}$ and $\mathrm{p}-\mathrm{I} \kappa \mathrm{B}-\alpha$. (b) The nuclear translocation of NF- $\kappa \mathrm{B}$ was observed by immunofluorescence microscopy.

exhibited potent antioxidant and anti-inflammatory effects in RAW 264.7 macrophages and the underlying molecular mechanism responsible was found to involve the inhibitions of NF- $\kappa \mathrm{B}$ and MAPK and Nrf2-mediated HO-1 induction.

Prolonged exposure to imbalances in homeostasis can result in a number of diseases. Western medicine generally focuses on diseased parts of the body, while oriental medicine seeks to identify and address the fundamental causes of diseases. The basic principle of traditional oriental medicine is to restore balance and harmony within the body and between individuals and their environments [15]. The use of traditional medicine and of complementary and alternative medicines has increased worldwide over the past decades and its use is supported by empirical evidence on safety and efficacy obtained over thousands of years [16]. In Korea, traditional herbal medicines are commonly in traditional Korean medicine and many formulas (prescriptions) have been developed involving combinations of herbal medicines. Components of these formulas are believed to act synergistically to complement beneficial effects and to neutralize the toxic or adverse effects of individual constituent herbs [17]. These formulas are based on traditional wisdom and experience, and their beneficial effects have been validated by scientific studies [17]. Recently, Kim et al. demonstrated the utility of the "Kun-Shin-Choa-Sa (Jun Chen Zuo Shi) theory," according to which multiple components of herbal medicines 


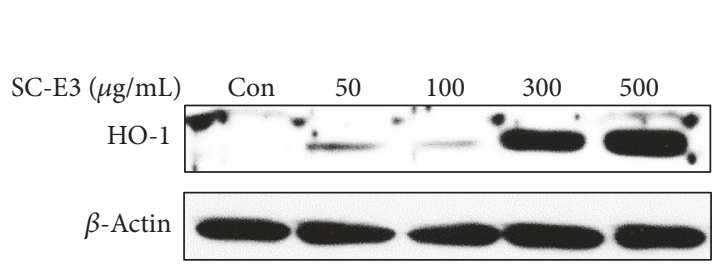

(a)

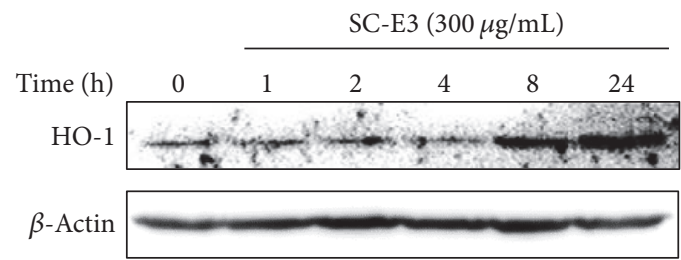

(b)
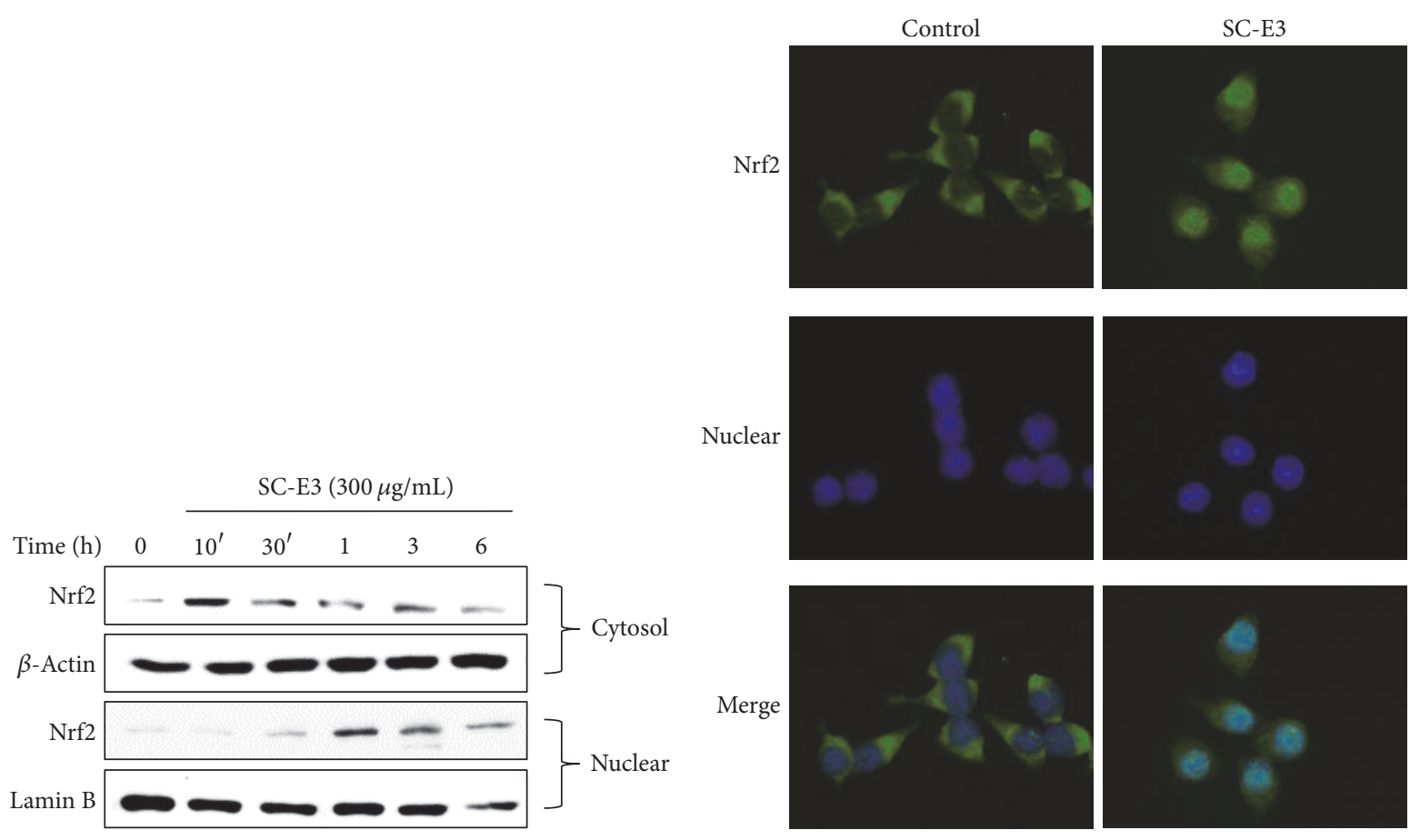

(c)

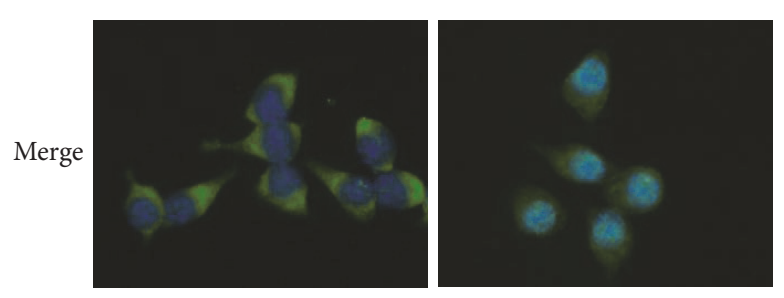

(d)

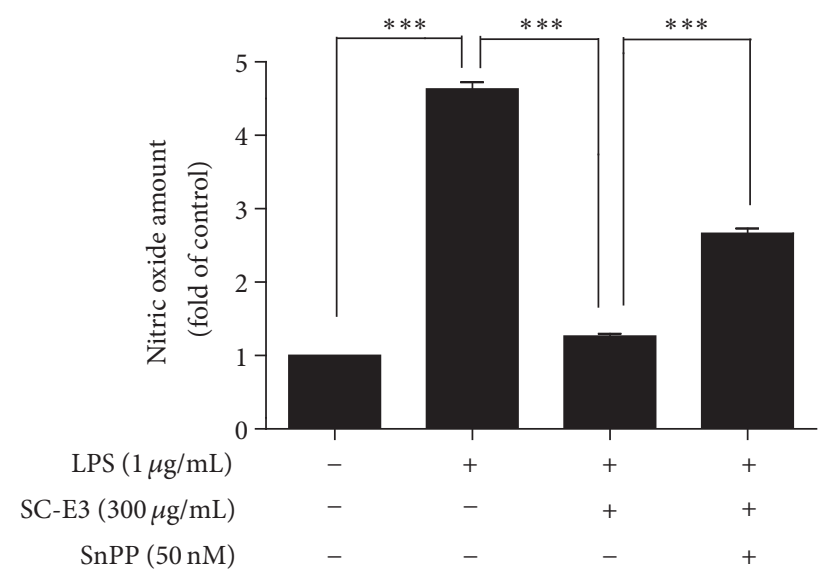

(e)

FIGURE 7: Effects of SC-E3 on the Nrf2/HO-1 signaling pathway in RAW 264.7 macrophages. (a) Induction of HO-1 by SC-E3. Cells were treated with different concentrations of SC-E3 $(50,100,300$, or $500 \mu \mathrm{g} / \mathrm{mL}$ ) for $18 \mathrm{~h}$. (b) Cells were treated with $300 \mu \mathrm{g} / \mathrm{mL}$ SC-E3 for the indicated times. (c) Nuclear accumulation of Nrf2 by SC-E3. Nrf2 was immunoblotted in the nuclear fractions of cells treated with $300 \mu \mathrm{g} / \mathrm{mL}$ of SC-E3 for the indicated times. (d) Immunofluorescence images of the nuclear translocation of Nrf2 induced by SC-E3. RAW 264.7 cells were treated with $300 \mu \mathrm{g} / \mathrm{mL}$ of SC-E3 for $3 \mathrm{~h}$. (e) Blocking of the inhibitory effect of SC-E3 on LPS-induced NO production by SnPP (an HO-1 inhibitor). RAW 264.7 cells were pretreated with SC-E3 $(300 \mu \mathrm{g} / \mathrm{mL})$ for $1 \mathrm{~h}$ in the presence or absence of SnPP $(50 \mathrm{nM}, 30 \mathrm{~min})$ and then stimulated with LPS $(1 \mu \mathrm{g} / \mathrm{mL})$ for $18 \mathrm{~h} .{ }^{* * *} p<0.001$ 


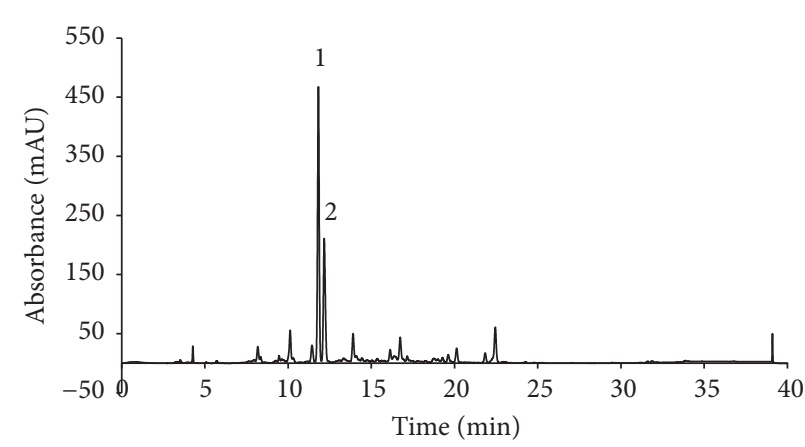

(a)

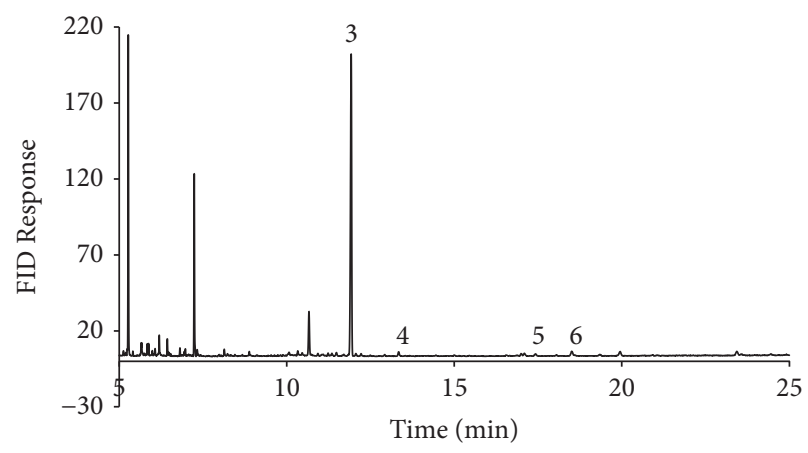

(b)

FIGURE 8: Identification of compounds from the ethanolic extract of SC-E3. (a) HPLC chromatogram of SC-E3 extract. The two compounds, geniposide and puerarin, were selected as marker compounds for quality control. The retention times of geniposide and puerarin were 12.183 and 11.830 min, respectively. (b) Representative GC-MS chromatogram for the analysis of fatty acids in SC-E3. Peaks: 1: puerarin, 2: geniposide, 3: pentadecanoic acid, 4: palmitic acid, 5: oleic acid, and 6: linoleic acid.

act synergistically by affecting multiple targets [18]. Based on prescriptions describing treatments for inflammation in Sanghanron, which addresses diseases caused by cold factors, and in Geumgweyoryak, which concerns the treatment of miscellaneous diseases, we designed SC-E3 using partly KunShin-Choa-Sa theory.

Of the five herbs constituting SC-E3, Bupleuri Radix, the dried roots of Bupleurum falcatum L. (Umbelliferae), is one of the most commonly used crude drugs as a febrifuge in China, Japan, and Korea [19]. Puerariae Radix, the dried root of Pueraria lobata Ohwi (Leguminosae), has been traditionally used to relieve fever and dysentery and has been reported to have antioxidant and anti-inflammatory effects [20, 21]. Coptidis Rhizoma, Coptidis japonica Makino (Ranunculaceae) is commonly used to treat dermatological disorders in oriental medicine. The anti-inflammatory effects of Coptidis Rhizoma, Gardeniae Fructus (Gardenia jasminoides Ellis, Rubiaceae), and Rhei Rhizoma (Rheum palmatum L., Polygonaceae) have been previously studied in RAW 264.7 cells [22-24]. Furthermore, a mixture of Coptidis Rhizoma and Rhei Rhizoma was shown to exert its antioxidant and anti-inflammatory effects by regulating $\mathrm{NF}-\kappa \mathrm{B}$ mediated inflammation in acute reflux esophagitis-induced rats [25].

The present study described the antioxidant and antiinflammation activities of SC-E3 in LPS-stimulated RAW 264.7 murine macrophages. LPS is one of the most potent innate immune-activating stimuli and induces the productions of cytokines and inflammatory mediators, such as NO and $\mathrm{PGE}_{2}$ in macrophages [26]. RAW 264.7 cells have been widely used in studies on macrophage cellular physiology because they are easily cultured, grow rapidly, and phenotypically resemble primary macrophages [27]. Therefore, LPSstimulated RAW 264.7 macrophages provide a good model for anti-inflammatory drug screening and for subsequently investigating effects on the signal pathways responsible for proinflammatory enzyme induction and for the production of proinflammatory cytokines [28]. In the present study, we found that SC-E3 suppressed iNOS and COX-2 protein levels and LPS-induced ROS generation and thereby suppressed the production of iNOS-derived $\mathrm{NO}$ and COX-2-derived $\mathrm{PGE}_{2}$ and the secretion of proinflammatory cytokines, that is, IL$1 \beta$, TNF- $\alpha$, and IL- 6 .

We tried to unearth the mechanism underlying the antiinflammatory effect of SC-E3 by focusing on intracellular signaling pathways, such as the MAPK, NF- $\kappa \mathrm{B}$, and Nrf2/HO1 pathways. MAPKs are a family of serine/threonine protein kinases that mediate fundamental biological processes and cellular responses to external stress signals [29]. LPS activates receptors by binding Toll-like receptor 4 , triggers the MAPK pathway, and thus, activates NF- $\kappa \mathrm{B}$ [29]. The NF- $\kappa \mathrm{B}$ pathway has long been considered a prototypical proinflammatory signaling pathway, because of the role of $\mathrm{NF}-\kappa \mathrm{B}$ in the expressions of proinflammatory genes, such as cytokines, chemokines, and adhesion molecules [30]. Our results show that SC-E3 inhibited the phosphorylation of MAPKs (i.e., ERK, JNK, and p38 MAPK), I $\kappa$ B- $\alpha$, and NF- $\kappa$ B by LPS stimulation. The nuclear translocation of $\mathrm{Nrf} 2$ is associated with the expressions of antioxidant proteins that protect against oxidative damage induced by inflammation [31]. Furthermore, HO-1, a gene targeted by Nrf2 in macrophages, is considered to have anti-inflammatory roles $[32,33]$. Moreover, studies have reported that various natural herb extracts attenuate LPS-induced inflammatory responses by modulating Nrf2mediated HO-1 induction and NF- $\kappa \mathrm{B}$ pathways [34-36]. Consistent with these studies, our results also showed that SC-E3 regulates $\mathrm{HO}-1$ induction via Nrf2 activation in macrophages. We also confirmed that treatment with SnPP (a HO-1 inhibitor) blocked the suppression of LPS-induced NO production by SC-E3. These results demonstrate that the antiinflammatory effects of SC-E3 are mediated by a multitargeting mechanism that involves the inhibitions of MAPK and $\mathrm{NF}-\kappa \mathrm{B}$ and Nrf2-mediated $\mathrm{HO}-1$ induction in macrophages.

Since SC-E3 is composed of five herbal medicines, it may exhibit a wide range of effects due to the combined effect of various ingredients. Geniposide and puerarin were identified and quantified as the major constituents in the ethanolic extract of SC-E3 by HPLC. These compounds have been reported to exhibit considerable antioxidant and 
anti-inflammatory activities in various studies [37-44]. Phenolic and flavonoid compounds have also been reported to exhibit antioxidant, anticancer, and anti-inflammatory activities [45-48]. In the present study, the total phenolic and total flavonoid contents in the crude extract from SC-E3 were determined using calibration curves of gallic acid and catechin. Our results suggest that polyphenols and flavonoids might be the contributors for the antioxidant and antiinflammatory activity of SC-E3 at least in part.

\section{Conclusion}

Taken together, the present study shows that the developed herbal formula SC-E3 has potent antioxidant and antiinflammatory effects on LPS-induced RAW 264.7 macrophages. Our results suggest that the beneficial effects of SCE3 may be due to its ability to inhibit the generation of excess ROS and the production of proinflammatory mediators and cytokines by suppressing the activation of MAPK and NF- $\kappa \mathrm{B}$ and by enhancing Nrf2-mediated HO-1 induction. Overall, our findings suggest SC-E3 may be considered a new prescription candidate for the treatment of inflammatory diseases. Further studies including preclinical studies are necessary to determine the clinical usefulness of SC-E3.

$\begin{array}{ll}\text { Abbreviations } \\ \text { ANOVA: } & \text { Analysis of variance } \\ \text { COX-2: } & \text { Cyclooxygenase-2 } \\ \text { DAPI: } & \text { 4,6-Diamidino-2-phenylindole } \\ \text { DCFH-DA: } & 2^{\prime}, 7^{\prime} \text {-Dichlorofluorescein-diacetate } \\ \text { DPPH: } & \text { 2,2-Diphenyl-1-picrylhydrazyl } \\ \text { ELISA: } & \text { Enzyme-linked immunosorbent assay } \\ \text { FBS: } & \text { Fetal bovine serum } \\ \text { FITC: } & \text { Fluorescein isothiocyanate } \\ \text { HO-1: } & \text { Heme oxygenase 1 } \\ \text { HPLC: } & \text { High-performance liquid chromatography } \\ \text { HRP: } & \text { Horseradish peroxidase } \\ \text { iNOS: } & \text { Inducible nitric oxide synthase } \\ \text { IL-1 } \beta: & \text { Interleukin-1 } \beta \\ \text { IL-6: } & \text { Interleukin-6 } \\ \text { LPS: } & \text { Lipopolysaccharide } \\ \text { MAPK: } & \text { Mitogen-activated protein kinase } \\ \text { MTT: } & \text { 3-(4,5-Dimethylthiazol-2-yl)-2,5- } \\ & \text { diphenyl-tetrazolium bromide } \\ \text { NO: } & \text { Nitric oxide } \\ \text { Nrf2: } & \text { Nuclear factor erythroid 2-related factor } 2 \\ \text { NF- } \kappa \text { B: } & \text { Nuclear factor-kappa B } \\ \text { PBS: } & \text { Phosphate-buffered saline } \\ \text { PGE }: & \text { Prostaglandin E } 2 \\ \text { ROS: } & \text { Reactive oxygen species } \\ \text { RT: } & \text { Room temperature } \\ \text { TNF- } \alpha: & \text { Tumor necrosis factor- } \alpha \\ \text { SD: } & \text { Standard deviation. } \\ & \end{array}$

\section{Conflicts of Interest}

The authors declare that there are no conflicts of interest regarding the publication of this article.

\section{Authors' Contributions}

Sun-Dong Park and Ju-Hee Lee as the principal director and study supervisor were responsible for the design of the study and obtained funding. Ju-Hee Lee and Soo Chil Lee participated in the study design and experiments and wrote the manuscript. Young-Won Kwon, Ju-Yeon Park, and Sung Yun Park carried out the experiments and the statistical analysis. All authors participating in the preparation of the manuscript approved the final version.

\section{Acknowledgments}

This research was supported by Basic Science Research Program through the National Research Foundation of Korea (NRF) funded by the Ministry of Education (2015R1D1A1A01060340).

\section{References}

[1] Z. Durackova, "Some current insights into oxidative stress," Physiological Research, vol. 59, no. 4, pp. 459-469, 2010.

[2] M. Mittal, M. R. Siddiqui, K. Tran, S. P. Reddy, and A. B. Malik, "Reactive oxygen species in inflammation and tissue injury," Antioxidants and Redox Signaling, vol. 20, no. 7, pp. 1126-1167, 2014.

[3] S. Becker, S. Mundandhara, R. B. Devlin, and M. Madden, "Regulation of cytokine production in human alveolar macrophages and airway epithelial cells in response to ambient air pollution particles: further mechanistic studies," Toxicology and Applied Pharmacology, vol. 207, no. 2, pp. S269-S275, 2005.

[4] N. Fujiwara and K. Kobayashi, "Macrophages in inflammation," Current Drug Targets-Inflammation \& Allergy, vol. 4, no. 3, pp. 281-286, 2005.

[5] R. A. Heller, M. Schena, A. Chai et al., "Discovery and analysis of inflammatory disease-related genes using cDNA microarrays," Proceedings of the National Academy of Sciences of the United States of America, vol. 94, no. 6, pp. 2150-2155, 1997.

[6] E. Bognar, Z. Sarszegi, A. Szabo et al., "Antioxidant and antiinflammatory effects in RAW264.7 macrophages of malvidin, a major red wine polyphenol," PLoS ONE, vol. 8, no. 6, Article ID e65355, 2013.

[7] S. H. Kim and H. J. Kim, "Literature review on sovereign, minister, assistant and courier theory, the basic principle of oriental medicine formula," The Journal of East-West Medicines, vol. 16, no. 1, pp. 5-21, 1991.

[8] D. Y. Choi, Comment on the Shang Han Lun, Daesung Publishing Company, Seoul, Korea, 1995.

[9] D. Y. Choi, J. K. Kim, and Y. H. Lyeom, Jin Gui Yao Lue, Dongguk university Press, Seoul, Korea, 2004.

[10] M. A. Gyamfi, M. Yonamine, and Y. Aniya, "Free-radical scavenging action of medicinal herbs from Ghana: Thonningia sanguinea on experimentally-induced liver injuries," General Pharmacology, vol. 32, no. 6, pp. 661-667, 1999.

[11] F. Liu, V. E. C. Ooi, and S. T. Chang, "Free radical scavenging activities of mushroom polysaccharide extracts," Life Sciences, vol. 60, no. 10, pp. 763-771, 1997.

[12] E. A. Ainsworth and K. M. Gillespie, "Estimation of total phenolic content and other oxidation substrates in plant tissues using Folin-Ciocalteu reagent," Nature Protocols, vol. 2, no. 4, pp. 875877, 2007. 
[13] J. Zhishen, T. Mengcheng, and W. Jianming, "The determination of flavonoid contents in mulberry and their scavenging effects on superoxide radicals," Food Chemistry, vol. 64, no. 4, pp. 555559, 1999.

[14] P. P. Tak and G. S. Firestein, "NF- $\kappa$ B: a key role in inflammatory diseases," Journal of Clinical Investigation, vol. 107, no. 1, pp. 7-11, 2001.

[15] S. A. Tabish, "Complementary and alternative healthcare: is it evidence-based?" International Journal of Health Sciences, vol. 2, no. 1, pp. V-IX, 2008.

[16] K.-H. Leem and H.-K. Park, "Traditional Korean medicine: now and the future," Neurological Research, vol. 29, supplement 1, pp. 3-4, 2007.

[17] H. Kumar, S.-Y. Song, S. V. More et al., "Traditional Korean east asian medicines and herbal formulations for cognitive impairment," Molecules, vol. 18, no. 12, pp. 14670-14693, 2013.

[18] H. U. Kim, J. Y. Ryu, J. O. Lee, and S. Y. Lee, “A systems approach to traditional oriental medicine," Nature Biotechnology, vol. 33, no. 3, pp. 264-268, 2015.

[19] F. Ikegami, M. Sumino, Y. Fujii, T. Akiba, and T. Satoh, "Pharmacology and toxicology of Bupleurum root-containing Kampo medicines in clinical use," Human and Experimental Toxicology, vol. 25, no. 8, pp. 481-494, 2006.

[20] M. C. Guerra, E. Speroni, M. Broccoli et al., "Comparison between Chinese medical herb Pueraria lobata crude extract and its main isoflavone puerarin: antioxidant properties and effects on rat liver CYP-catalysed drug metabolism," Life Sciences, vol. 67, no. 24, pp. 2997-3006, 2000.

[21] D. W. Lim, C. Lee, I.-H. Kim, and Y. T. Kim, "Anti-inflammatory effects of total isoflavones from Pueraria lobata on cerebral ischemia in rats," Molecules, vol. 18, no. 9, pp. 10404-10412, 2013.

[22] A. Remppis, F. Bea, H. J. Greten et al., "Rhizoma coptidis inhibits LPS-induced MCP-1/CCL2 production in murine macrophages via an AP-1 and NF $\kappa \mathrm{B}$-dependent pathway," Mediators of Inflammation, vol. 2010, Article ID 194896, 8 pages, 2010.

[23] J. Cha and E. Lim, "Effects of gardeniae fructus on cytokines in mouse macrophage," The Journal of Oriental Obstetrics and Gynecology, vol. 27, no. 1, pp. 1-16, 2014.

[24] M. S. Cheon, T. Yoon, G. Choi et al., "Comparative study of extracts from rhubarb on inflammatory activity in raw 264.7 cells," Korean Journal of Medicinal Crop Science, vol. 17, no. 2, pp. 109-114, 2009.

[25] O. J. Kwon, M. Y. Kim, S. H. Shin et al., "Antioxidant and antiinflammatory effects of rhei rhizoma and coptidis rhizoma mixture on reflux esophagitis in rats," Evidence-Based Complementary and Alternative Medicine, vol. 2016, Article ID 2052180, 13 pages, 2016.

[26] Y. Yang, S. Li, Q. Yang et al., "Resveratrol reduces the proinflammatory effects and lipopolysaccharide-induced expression of HMGB1 and TLR4 in RAW264.7 cells," Cellular Physiology and Biochemistry, vol. 33, no. 5, pp. 1283-1292, 2014.

[27] M. R. Maurya, S. Gupta, X. Li et al., "Analysis of inflammatory and lipid metabolic networks across RAW264.7 and thioglycolate-elicited macrophages," Journal of Lipid Research, vol. 54, no. 9, pp. 2525-2542, 2013.

[28] S.-L. Liu, J.-S. Deng, C.-S. Chiu et al., "Involvement of heme oxygenase-1 participates in anti-inflammatory and analgesic effects of aqueous extract of Hibiscus taiwanensis," EvidenceBased Complementary and Alternative Medicine, vol. 2012, Article ID 132859, 13 pages, 2012.
[29] J. M. Kyriakis and J. Avruch, "Mammalian mitogen-activated protein kinase signal transduction pathways activated by stress and inflammation," Physiological Reviews, vol. 81, no. 2, pp. 807$869,2001$.

[30] T. Lawrence, "The nuclear factor NF- $\kappa$ B pathway in inflammation," Cold Spring Harbor perspectives in biology, vol. 1, no. 6, Article ID a001651, 2009.

[31] Q. Ma, "Role of Nrf2 in oxidative stress and toxicity," Annual Review of Pharmacology and Toxicology, vol. 53, pp. 401-426, 2013.

[32] D. Willis, A. R. Moore, R. Frederick, and D. A. Willoughby, "Heme oxygenase: a novel target for the modulation of the inflammatory response," Nature Medicine, vol. 2, no. 1, pp. 8790, 1996.

[33] K. Itoh, M. Mochizuki, Y. Ishii et al., "Transcription factor Nrf2 regulates inflammation by mediating the effect of 15-Deoxy$\Delta^{12,14}$-prostaglandin $\mathrm{J}_{2}$," Molecular and Cellular Biology, vol. 24, no. 1, pp. 36-45, 2004.

[34] Y. Shinkai, I. Yamanaka, H. H. T. Duong, N. T. Quynh, Y. Kanaho, and Y. Kumagai, "Garcinia vilersiana bark extract activates the Nrf2/HO-1 signaling pathway in RAW264.7 cells," Journal of Toxicological Sciences, vol. 38, no. 6, pp. 875-878, 2013.

[35] O. J. Kwon, B. K. Choo, J. Y. Lee et al., "Protective effect of Rhei Rhizoma on reflux esophagitis in rats via Nrf2-mediated inhibition of NF- $\kappa \mathrm{B}$ signaling pathway," BMC Complementary and Alternative Medicine, vol. 16, no. 1, article 7, 2016.

[36] Y. H. Jeong, Y.-C. Oh, W.-K. Cho, N.-H. Yim, and J. Y. Ma, "Anti-inflammatory effect of rhapontici radix ethanol extract via inhibition of NF- $\kappa$ B and MAPK and induction of HO-1 in macrophages," Mediators of Inflammation, vol. 2016, Article ID 7216912, 2016.

[37] Q. Shi, J. Cao, L. Fang et al., "Geniposide suppresses LPSinduced nitric oxide, $\mathrm{PGE}_{2}$ and inflammatory cytokine by downregulating NF- $\kappa \mathrm{B}, \mathrm{MAPK}$ and AP-1 signaling pathways in macrophages," International Immunopharmacology, vol. 20, no. 2, pp. 298-306, 2014.

[38] X. Song, W. Zhang, T. Wang et al., "Geniposide plays an anti-inflammatory role via regulating TLR4 and downstream signaling pathways in lipopolysaccharide-induced mastitis in mice," Inflammation, vol. 37, no. 5, pp. 1588-1598, 2014.

[39] J. Wang, Y. Zhang, R. Liu, X. Li, Y. Cui, and L. Qu, "Geniposide protects against acute alcohol-induced liver injury in mice via up-regulating the expression of the main antioxidant enzymes," Canadian Journal of Physiology and Pharmacology, vol. 93, no. 4, pp. 261-267, 2015.

[40] J. Ren and S. H. Chung, "Anti-inflammatory effect of $\alpha$-linolenic acid and its mode of action through the inhibition of nitric oxide production and inducible nitric oxide synthase gene expression via NF- $\kappa$ B and mitogen-activated protein kinase pathways," Journal of Agricultural and Food Chemistry, vol. 55, no. 13, pp. 5073-5080, 2007.

[41] R. Anand and G. Kaithwas, "Anti-inflammatory potential of alpha-linolenic acid mediated through selective COX inhibition: computational and experimental data," Inflammation, vol. 37, no. 4, pp. 1297-1306, 2014.

[42] N. Xie, W. Zhang, J. Li et al., " $\alpha$-linolenic acid intake attenuates myocardial ischemia/reperfusion injury through antiinflammatory and anti-oxidative stress effects in diabetic but not normal rats," Archives of Medical Research, vol. 42, no. 3, pp. 171-181, 2011.

[43] Y. P. Hwang, C. Y. Choi, Y. C. Chung, S. S. Jeon, and H. G. Jeong, "Protective effects of Puerarin on carbon tetrachloride-induced 
hepatotoxicity," Archives of Pharmacal Research, vol. 30, no. 10, pp. 1309-1317, 2007.

[44] S.-Y. Wei, Y. Chen, and X.-Y. Xu, "Progress on the pharmacological research of puerarin: a review," Chinese Journal of Natural Medicines, vol. 12, no. 6, pp. 407-414, 2014.

[45] S. Kumar and A. K. Pandey, "Chemistry and biological activities of flavonoids: an overview," The Scientific World Journal, vol. 2013, Article ID 162750, 16 pages, 2013.

[46] J. Dai and R. J. Mumper, "Plant phenolics: extraction, analysis and their antioxidant and anticancer properties," Molecules, vol. 15, no. 10, pp. 7313-7352, 2010.

[47] H. K. Biesalski, "Polyphenols and inflammation: basic interactions," Current Opinion in Clinical Nutrition and Metabolic Care, vol. 10, no. 6, pp. 724-728, 2007.

[48] S. Cimino, G. Sortino, V. Favilla et al., "Polyphenols: key issues involved in chemoprevention of prostate cancer," Oxidative Medicine and Cellular Longevity, vol. 2012, Article ID 632959, 8 pages, 2012. 


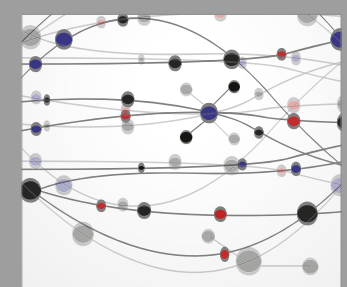

The Scientific World Journal
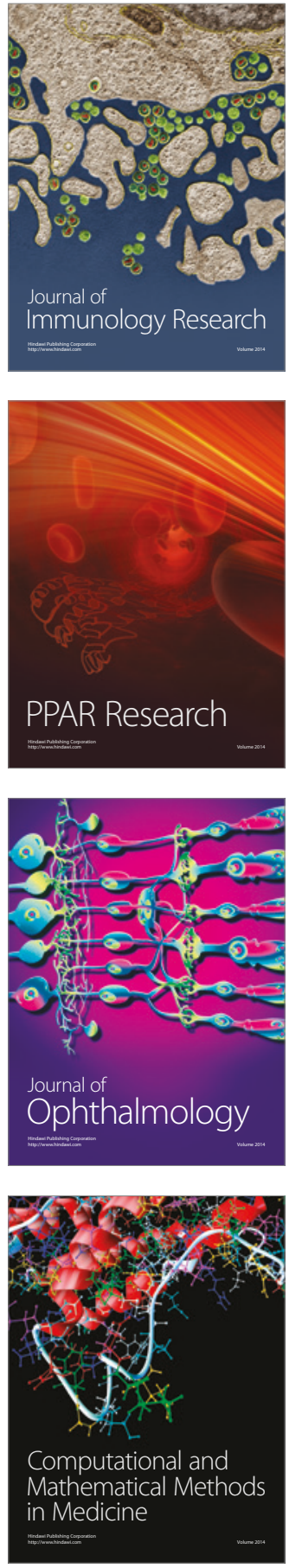

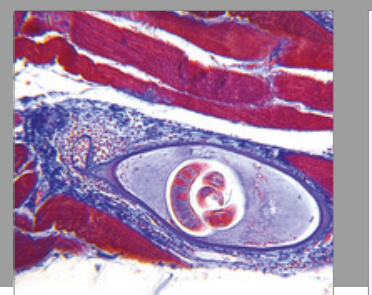

Gastroenterology Research and Practice
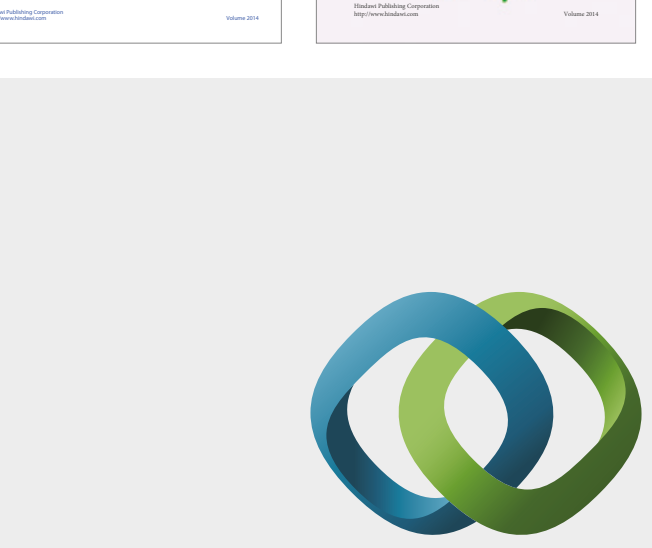

\section{Hindawi}

Submit your manuscripts at

https://www.hindawi.com
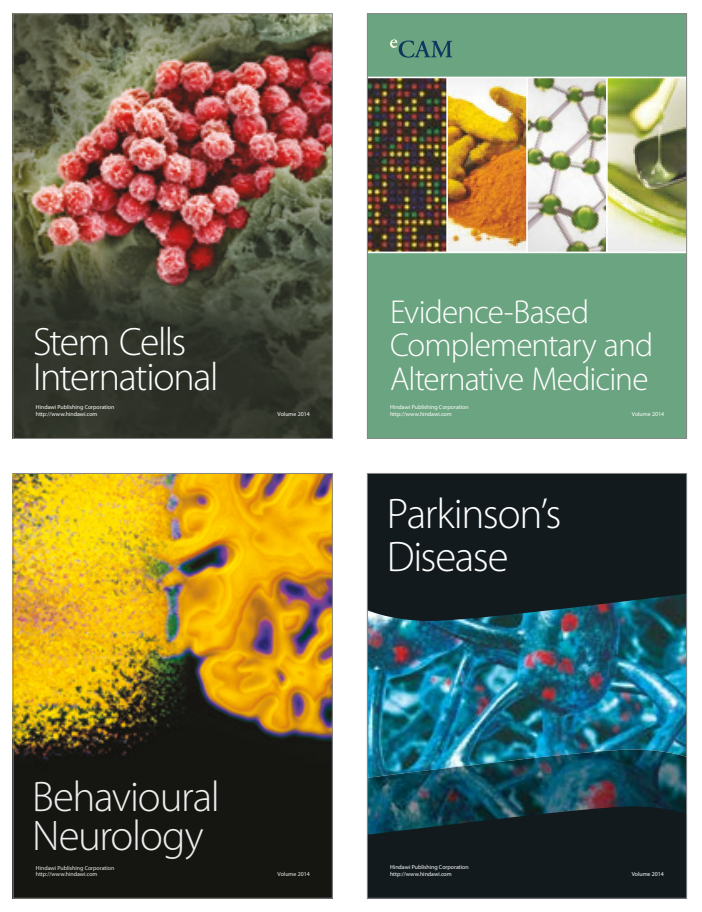
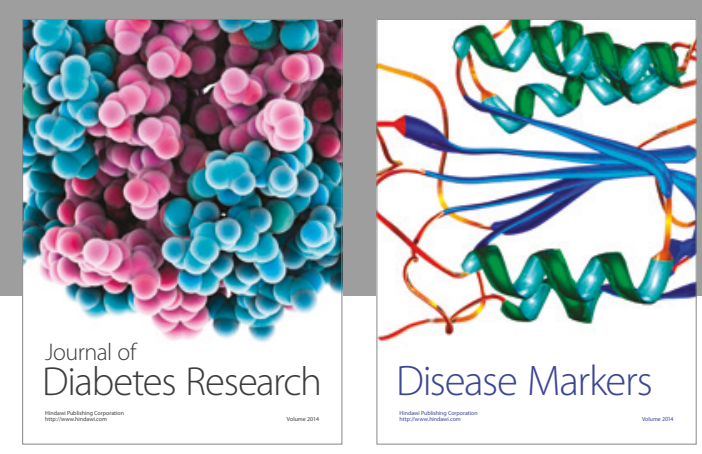

Disease Markers
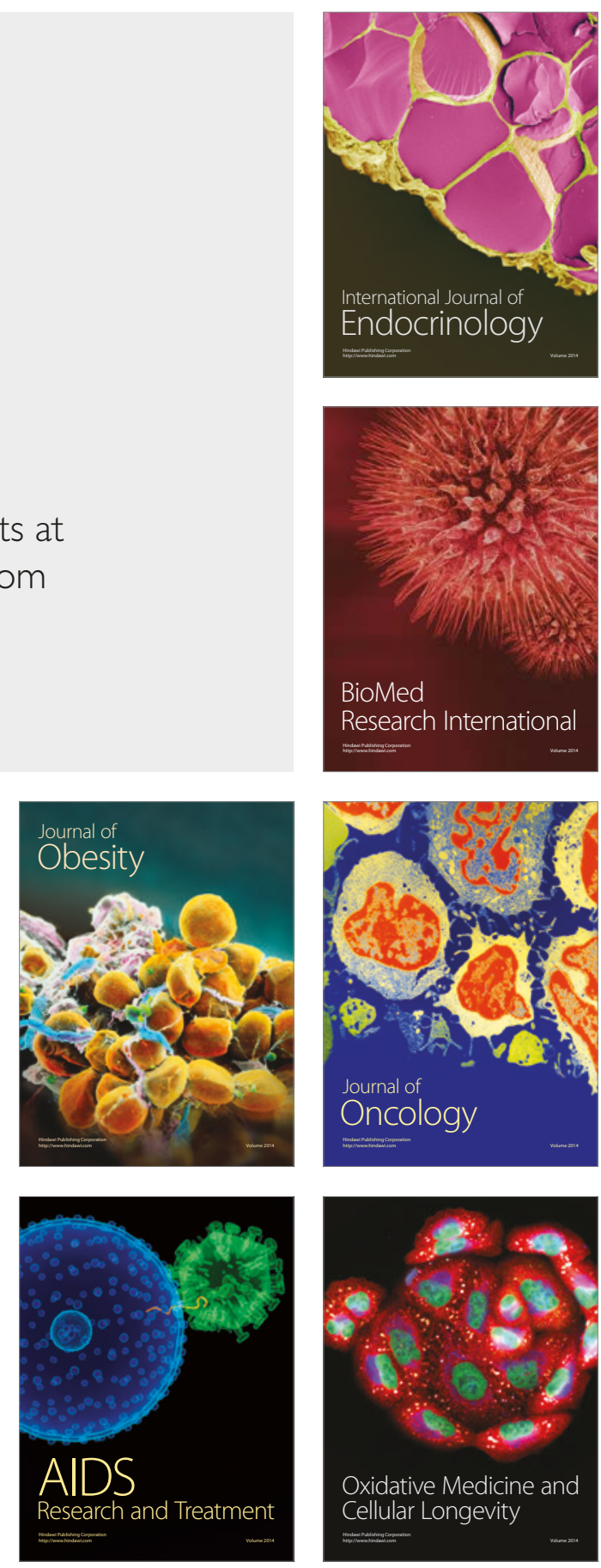